\title{
DE LEITOR PARA LEITOR: RELAÇÕES ÉTNICO-RACIAIS NO ENSINO DA LITERATURA INFANTIL E JUVENIL NO BRASIL
}

\author{
Miria Gomes Oliveira*
}

RESUMO: Este artigo discute relações étnico-raciais no ensino de literatura infantil e juvenil no Brasil. Com base nas leis 10.639/2003 e 11.645/2008, que determinam o ensino da História, da Arte e da Cultura Africana, Afro-brasileira e das Nações Indígenas, buscamos problematizar o projeto de pesquisa aplicada De Leitor para Leitor considerando a eficácia das leis citadas e a recepção dos livros literários africanos, afro-brasileiros e indígenas reunidos no Kit-Afro: uma política afirmativa de democratização do acesso à produção literária para a diversidade, implementada pela Rede Municipal de Ensino de Belo Horizonte. Nossas discussões são norteadas por estudos sobre relações etnicoraciais no Brasil (GOMES, 2012; SILVA), Análise Crítica do Discurso (VAN DIJK, 2008), Ensino da literatura (OLIVEIRA, 2015; 2016), Interculturalidade e Pedagogias Descoloniais (HOPENHAY, 2009; WALSH, 2017). A partir de resenhas e avaliações produzidas, apontamos a tomada de consciencia linguístico-ideológica dos alunos envolvidos.

PALAVRAS-CHAVE: Educação étnico-racial; Ensino da literatura infantil e juvenil; Políticas afirmativas

\section{Introdução}

Este texto discute o ensino da literatura infantil e juvenil no Brasil a partir do projeto de pesquisa aplicada De leitor para leitor: letramento literário, diversidade e relações étnicoraciais no $2^{\circ}$ ciclo de formação. A sanção das Leis 10.639/03 e 11.645/2008, que tornaram obrigatório o ensino de história e cultura africana e de nossos povos nativos no sistema de educação básica brasileiro, especialmente nas disciplinas de história, português e artes, é resultado de um longo caminho de lutas e reivindicações do Movimento Negro brasileiro e de questionamentos ao mito da democracia racial ou racismo à brasileira (FERNANDES,

\footnotetext{
* Doutora em Estudos Linguísticos pela Universidade Federal de Minas Gerais (UFMG). Professora da FAEUFMG, onde integra a equipe de pesquisadores do CEALE/GPELL/FAE/UFMG e do NERA/FAE/UFMG.
} 
1964), cristalizado e contraditoriamente aliado à manutenção de estruturas socioeconômicas nas quais as desigualdades fundamentam-se em bases raciais inequívocas em um país em que os negros são maioria em todos os setores e lugares socialmente desprestigiados. As reflexões sobre o Mito da Democracia Racial inauguradas por Florestan Fernandes em sua tese de doutoramento e presentes em seu livro A integração do Negro na Sociedade de classes (1966) embasam pesquisas de diversos campos do conhecimento dedicados ao entendimento das formas como o racismo opera no Brasil a partir do nascimento do Estado-Nação brasileiro no século XIX (GOMES: 2005, 2013; GUIMARÃES: 1999, 2002, 2006 e MUNANGA: 1999). Os autores apontam fatos históricos e questões políticas internas e externas que nos levam a compreender o Mito da Democracia Racial como uma expressão sinônima de negação do racismo que estrutura a sociedade brasileira, mantendo as desigualdades de oportunidades entre brancos e negro.

Buscamos, assim, reconhecer, preservar e dar visibilidade às contribuições da cultura negra e indígena na formação da sociedade brasileira. Diante da continuidade da luta pela efetivação das leis nos últimos anos, apontamos, inicialmente, três questões primordiais a serem assumidas no ensino da literatura: a primeira refere-se à revisão de concepções estereotipadas do pensamento social brasileiro, marcada pelo falso mito da democracia racial, que resultou da negação do racismo brasileiro. A segunda, refere-se à postura afirmativa da identidade negra como fundamento de deslocamentos discursivos. A terceira, é a construção de reflexões teórico-metodológicas que nos permitam conhecer e poder dizer sobre o Continente Africano: sobre nossas histórias cruzadas, sobre a vida dos africanos no Brasil e em contextos diaspóricos e sobre os saberes produzidos e acumulados ao redor do mundo (WALKER, 2019). Enfatizamos, assim, os diálogos sul/sul (SANTOS, 2010) e interculturais (HOPENNHAY, 2009) que incentivam a cooperação horizontal entre países que ainda vivem a exploração econômica de países da Comunidade Européia e dos Estados Unidos da América do Norte. No Brasil, a ideologia colonial continua a ser disseminada nas instituições inauguradas pelo Estado Nação no final do século XIX, dentre 
elas a escola tendo em vista a desconstrução do racismo nos processos de formação de leitores literários.

\section{Educação étnico-racial, análise crítica do discurso e o ensino da literatura infantil e juvenil no Brasil}

A canonização de obras literárias tem na escola um dos seus principais contextos de legitimação desde o século XIX. Ao longo do século XX, a produção literária e o ensino da literatura no Brasil são permeados por discursos fundantes da nação brasileira como o discurso da democracia racial e do branqueamento pela miscigenação (LABORNE, 2014). A canonização da obra de Monteiro Lobato, um higienista assumido, como clássico da literatura infantil e juvenil é um exemplo de propagação desses discursos. Práticas racistas nos âmbitos ideológicos, políticos e sociais perduram na sociedade brasileira em nossos dias e sustentam a exploração econômica em um país cuja população trabalhadora é majoritariamente preta e parda e, quanto mais escura a cor da pele, maior o risco social enfrentado cotidianamente. A negação do racismo à brasileira por críticos literários e educadores denota a reafirmação deste mito. Argumentos como: literatura é somente um praz̧er estético ou era comum naquele tempo reiteram o mito da democracia racial no meio acadêmico brasileiro.

Na contramão dessa História, entre 2003 e o Golpe de 2016, as políticas públicas implementadas no Brasil procuraram criar ações para combater desigualdades e discriminações no espaço escolar. A partir da instituição da obrigatoriedade pelo Conselho Nacional de Educação (CNE), em 2003, inicia-se uma política pública não só de educação, mas também de afirmação da identidade, da memória e da cultura negra:

$\int 1^{\circ}$ A Educação das Relações Étnico-Raciais tem por objetivo a divulgação e produção de conhecimento, bem como de atitudes, posturas e valores que eduquem cidadãos quanto à pluralidade étnico-racial, tornando-se capazes de interagir e de negociar objetivos comuns que garantam, a todos, respeito aos direitos da democracia brasileira. (CNE n ${ }^{\circ}$ 3/2004, BRASIL, 2004a) 
As Diretrizes Curriculares Nacionais para o Ensino de História e Cultura AfroBrasileira e Africana, nos termos do Parecer CNE n³/2004 (BRASIL, 2004a) e da respectiva Resolução CNE/CP1/2004, determina que a temática da educação das relações étnico-raciais seja um dos eixos dos projetos políticos-pedagógicos das instituições de ensino, seja básico ou superior, servindo de base para "avaliar a qualidade das condições de oferta de educação por escolas e universidades [tem-se] entre os quesitos a observar, a realização de atividades intencionalmente dirigidas à educação das relações étnico-raciais” (GONÇALVES E SILVA, 2011, p. 12). A legislação destaca que o processo de educação das relações étnico-raciais pretende romper com preconceitos, sentimentos de inferioridade ou superioridade que sustentam as posições hierárquicas forjadas em desigualdades raciais, sociais e econômicas. Mais do que uma questão cultural, esse processo permite que nossas crianças e jovens se identifiquem e se sintam representadas em diferentes contextos sociais.

Diante disso, buscamos na Análise Crítica do Discurso referências teóricometodológicas pelo seu comprometimento com o desvendar de relações de poder em determinado tempo e espaço. Sua base assenta-se em teóricos da filosofia da linguagem (BAKHTIN,1992; WITTGENSTEIN,1953; AUSTIN,1975; SEARLE,1983), analistas do discurso franceses (PECHEUX, 1983), filósofos e sociólogos (MARX; ENGELS, 1998; FOUCAULT,2012; BOURDIEU,1982) e precursores da escola de Frankfurt. Especificamente no campo da educação, estudos da sociolinguística e estudos da narrativa (LABOV, 1972; GUMPERZ, 1982; HEATH, 1986; BRUNER, 1990, dentre outros) são obras precursoras que romperam com a visão prescritivista de teorias educacionais e se voltaram para a realidade social das práticas educacionais, com o objetivo de nelas intervir. A ACD provê instrumentos que nos permitem lidar com a complexidade dos contextos educacionais e analisar as práticas pedagógicas em tais contextos no mundo desigualmente globalizado porque questiona, como nos lembra Van Dijk (2008):

1. Formas de poder que legitimam relações assimétricas de poder;

2. Formas de poder que se encontram por trás de relações assimétricas de poder, e; 
3. Formas de poder que medeiam diretamente as relações sociais.(p. $10)$

Esses questionamentos veem ao encontro de nossa pesquisa na medida em que a efetividade e eficácia da Lei 10.639/03 é, em si mesma, uma forma de questionar a hegemonia eurocêntrica dos currículos de cursos de formação de professores no Brasil. Ao questionar as formas de poder que subjazem a relações assimétricas, a ACD traz o papel da linguagem já que essas relações produzem e/ou reproduzem significados (racistas) que se traduzem em ações de exclusão da população negra de lugares de prestígio social e econômico no Brasil.

Para além de criticar, a ACD busca formas de ação e reação à dominação na dialética material do cotidiano. Procura desenhar e forjar alternativas de "ser, agir, representar e interagir no mundo, com o objetivo de banir formas de dominação e opressão sociais” (ROGERS, 2004. p. 3). Nesta perspectiva, discurso é uma prática social que implica em modos de ação em relação ao outro no mundo, constituindo e construindo significados e ações, em uma via de mão dupla: as representações sociais estão sempre em luta com práticas políticas e ideológicas. Trata-se de uma análise não só do que é dito como também do não dito em textos orais ou escritos.

Busca-se, assim, desvendar como padrões morais e estéticos veiculados através de signos em redes semióticas constroem identidades. Interessam-nos as práticas sociais autênticas de linguagem, sejam elas escritas e/ou orais. Esse movimento pode ser melhor entendido através da metáfora da retenção: a capacidade humana de recontextualizar o que é aprendido tendo em vista agir no mundo material: recontextualizar o discurso é perceber seus efeitos ideológicos e, ao mesmo tempo, questioná-lo, nas formas especificas do contexto em questão. $\mathrm{Na}$ verdade, "forja-se uma relação distinta com um discurso desconhecido, sendo também uma forma de apropriação discursiva desse outro" (FAIRCLOUGH, 2008. p. 124).

A ampliação do debate sobre o racismo a brasileira a partir da promulgação da lei 10.639/03 contribui para a recontextualização de discursos racistas na medida em que 
implicam em agir no mundo em momentos de decisão como na seleção de textos, abordagens de ensinar e posicionamentos ideológicos do professor. O contato entre discursos divergentes gera a interdiscursividade, entendida como presença ou traços de um discurso em outro e pode levar a desestabilização de discursos hegemônicos ou estáveis. Ao interagirem, os sujeitos encontram-se em uma zona de negociação e conflitos em que novos conhecimentos são produzidos e identidades afirmadas.

Ao assumirmos a educação étnico-racial de educadores e educandos de literatura como questão central, reportamo-nos a um tema historicamente escamoteado por manobras discursivas da elite intelectual brasileira. Presenciamos, no Brasil de hoje, a luta entre a recusa em discutir assuntos ligados a questões étnico-raciais e a proeminência da cultura popular gradativamente motivando estudantes, membros das comunidades de base e universidades a manterem pontos de resistência antirracista. Ainda que diante de um longo caminho a ser percorrido, a construção de pedagogias da diversidade e de literaturas munidas de símbolos e histórias que permitam a construção de outros discursos valorativos, de outros paradigmas críticos já fazem parte da Educação Étnico-racial no Brasil.

É importante ressaltar o conceito de raça, ao qual nos referimos: raça como uma categoria social. Trata-se de um marcador social que define diferenças culturais e determina desigualdades econômicas entre a população negra e branca em nosso país. Não se trata, portanto, do conceito biologizante, demarcado por diferenças genéticas inexistentes. Os processos de racialização fenotípica se estabeleceram principalmente a partir do século XIX, em função da concepção eugenista de ciência inglesa e foi propagada de diferentes formas em todo o planeta em que vivemos. No Brasil, esse processo é marcado pela cor da pele: quanto mais retinta, mais sujeito ao racismo e à discriminação social estará o indivíduo.

Diante disso, buscamos contribuir para o ensino da literatura no Brasil a partir da discussão da pesquisa aplicada De leitor para leitor, tendo em vista seu objetivos de analisar a recepção dos livros de literatura africana e afro-brasileira do chamado Kit Afro: uma política de democratização do acesso a produção literária para a diversidade, implementada pela 
Rede Municipal de Ensino de Belo Horizonte (RME-BH), capital do estado de Minas Gerais. Entre os anos de 2004 e 2019, 431 títulos foram distribuídos às bibliotecas escolares e municipais da cidade.

A pesquisa visou divulgar esse acervo e formar leitores para a complexidade tecnológica dos modos de ler, impressos ou em tela, que hoje se proliferam em nossa aldeia global. Além disso, a parceria com a Escola Municipal Deputado Milton Sales (EMDMS) buscou construir atividades didáticas que suavizassem a abrupta mudança de práticas de leitura literária entre o $4^{\circ}$ e $6^{\circ}$ ano do Ensino Fundamental, fossem elas relacionadas à abordagem metodológica assumida pela professora-mediadora, fossem no que diz respeito ao conteúdo, à dimensão ideológica e design gráfico de livros destinados a alunos do $2^{\circ}$ Ciclo de formação.

Antes de ir a campo, algumas questões foram levantadas: como propor práticas de letramento literário que considerem a identidade étnico-racial de sujeitos-leitores? Como viabilizar diálogos sobre educação étnico-racial entre a universidade e a escola básica? Como a diversidade constitutiva de nossa realidade social está refletida nas vozes dos alunos do $2^{\circ}$ Ciclo? Em que sentido a mediação do professor pode contribuir para que essas vozes sejam ouvidas? Como explorar o potencial ético-estético de textos literários na formação de leitores críticos? Como a tecnologia pode nos ajudar a formar leitores e a divulgar acervos literários de qualidade, ampliando as referências bibliográficas da comunidade escolar?

\section{Formação de leitores para a diversidade cultural}

O combate a todas as formas de discriminação, racismo e preconceito exige trabalho constante e ações afirmativas que visem exercitar o direito à educação para todos. Muitos estudos vêm sendo feitos no sentido de perceber o papel da produção literária para crianças e jovens no Brasil atual, já que essa produção pode contribuir para o cumprimento das Leis 10.639/03 e 11.645/08. Entre eles, destacamos SILVA (2007) que, ao pesquisar marcas de racismo em livros didáticos e literatura infantil e juvenil, constata a presença do personagem negro, na maioria das estórias, tratado como objeto da ação do outro, em 
contraponto com os personagens brancos tratados com atuação e autonomia. Em Oliveira (2017; 2018), discutimos a racialização da literatura brasileira na obra de Machado de Assis e Carolina de Jesus, notando como o racismo estruturante deve ser revelado e recontextualizado a partir de mediações críticas em sala de aula. Esse processo está diretamente ligado a efetivos diálogos Sul/Sul, ou seja, diálogos estabelecidos em relações horizontais do ponto de vista das Epistemologias do Sul (SANTOS, 2010) - em que todos nós podemos aprender com as culturas do Sul, e não apenas com a imposição cultural dos países situados acima da linha do equador do mundo ocidental.

Atendendo às diretrizes da lei, a RME-BH instituiu, durante o ano de 2004, o Núcleo de Relações Étnico-Raciais e de Gênero da Secretaria Municipal de Educação (SMED), com objetivo de "atender à demanda crescente de formação e subsidiar o trabalho com a temática étnico-racial” (SMED, 2013, p. 5). Entre as funções do núcleo está a distribuição de acervo literário para as bibliotecas escolares e municipais que contemple as temáticas pertinentes às leis supracitadas por meio do Kit Afro, forma como é conhecido o conjunto de livros de literatura africana, afro-brasileira e Indígena enviados às bibliotecas.

Em nossa parceria com a EMDMS, tomamos os livros dos Kits enviados às bibliotecas, desde o ano de 2004, para entendermos a recepção dessas obras pelos alunos, partindo do pressuposto de que livros infantis e juvenis são artefatos culturais influentes nos quais imagens podem ser introduzidas, sustentadas e desafiadas. Entendemos os artefatos culturais como resultantes de processos de construção social em que circulam discursos capazes de naturalizar ou questionar verdades (JOOSAN, 2017, p. 76). Neles, aprendemos maneiras de ver, ser e estar no mundo. Os livros literários infantis e juvenis são considerados artefatos culturais porque propagam significados e práticas culturalmente construídos, podendo vir a influenciar na dinâmica social por meio de textos verbais e não verbais. Eles são produtores e reprodutores do currículo cultural de determinada sociedade (SAMPAIO; MAGALHÃES; FÉRES-CARNEIRO, 2018) e reúnem imagens capazes de impor padrões éticos e estéticos. Para analisa-los é preciso criticar a cultura existente como um pressuposto básico para a instauração de uma nova cultura (FREIRE, 1997, 68). 
O conceito de vozes foi fundamental para a realização da pesquisa. Ele nos auxiliou a entender a interpretação dos alunos vistos como sujeitos que falam de determinado lugar social dentro de sua comunidade de práticas culturais, práticas essas que são delimitadas por questões econômicas. As interações em sala de aula envolvem o reconhecimento mútuo dos papéis entre os falantes. Assim, a professora supervisora e a professora coordenadora tinham o compromisso prévio de garantir que os alunos se expressassem através das "vozes" de suas comunidades, ao mesmo tempo em que trariam outras referências socioculturais em cada contato interativo com o texto literário em sala de aula.

Em nosso entendimento, as "vozes" estão constantemente em transformação a cada nova situação de fala. O significado só existe quando duas ou mais vozes entram em contato, quando a vOz do ouvinte responde à voz do falante. A personalidade que fala envolve alguém que toma uma certa perspectiva ou pertence a categorias culturais e sociais particulares. Uma enunciação (falada, ou escrita) se expressa sempre de um ponto de vista (uma voz). Compreender a enunciação dos alunos envolveu um processo em que enunciações são buscadas e confrontadas entre si. A esse processo, Bakhtin (1992) deu o nome de "adressividade”, ou seja, o processo que marca a atitude de quem ouve em relação ao sujeito que fala.

O conceito de vozes foi também uma ferramenta metodológica. A escuta da vOz dos alunos foi tomada como condição do processo de ensino-aprendizagem do texto literário. A interação entre as vozes do conhecimento acadêmico-literário da professora e de conhecimento de mundo dos estudantes viabilizou o questionamento do discurso autoritário da imposição cultural canônica. Aos poucos, e em interações nem sempre marcadas pelo consenso, notamos como educandas e educandos são capazes de falar em suas próprias palavras, de se expressarem e desafiarem os campos do conhecimento e do poder. Nesta perspectiva, entendemos voz. como o espaço de produção de significados. Um espaço em que a percepção da diferença entre suas vozes e a voz do outro, presente na linguagem padrão do texto literário, produz conscientização a partir de seus próprios lugares identitários. 
As afirmações de que tudo que é ideológico possui um valor semiótico e de que a própria consciência só pode surgir e se afirmar como realidade mediante a encarnação material em signos (BAKHTIN, 1992. P. 32-33) são nosso ponto de partida ao refletir o ensino da leitura e da escrita em contextos escolares.

Os estudos do Círculo de Bakhtin situam a ideologia no domínio dos signos, afirmando que a tomada de consciência se dá através de sua manifestação semiótica e que seu conteúdo é determinado por fatores sociais e subjetivos: a diferenciação ideológica, o crescimento do grau de consciência são diretamente proporcionais à firmeza e à estabilidade da orientação social. (BAKHTIN,1992. P. 115). Dessa forma, a tomada de consciência e a elaboração ideológica, dentre as quais oscila nossa atividade mental do eu e do nós, têm sempre uma orientação social de caráter apreciativo, o que nos faz relacioná-las à formação de nosso senso crítico. Com isso, os estudos do círculo nos levam a perceber, nas situações de ensino e aprendizagem, a interação de várias consciências por ele apontadas na edificação do romance dostoievskiano. Nas interações se dá a formação da consciência pois:

O pensamento humano só se torna pensamento autêntico, isto é, ideia, sob as condições de um contato vivo com o pensamento dos outros, materializado na vOz dos outros, ou seja, na consciência dos outros expressa na palavra. É no ponto desse contato entre vozesconsciências que nasce e vive a ideia”. (BAKHTIN, 1997b, p. 86)

Se a diversidade dos sujeitos presentes em uma sala de aula marca esse espaço como constitutivamente heterogêneo e diversificado, faz-se necessário vê-la enquanto um local de formação da consciência, e, um local onde diferentes discursos se interceptam e são, ao mesmo tempo, cruzados por relações de poder.

Sendo a escola uma instituição social, a determinação das funções dos sujeitos se dá previamente. No entanto, ainda que a polarização professores e alunos, isto é, a determinação prévia de dois papéis fixos atuando como uma força centrípeta em sala de aula, queira direcionar as relações de poder decorrentes dos papeis institucionais, não consegue apagar o conflito intra e interindividual entre as vozes internalizadas de uma 
sociedade heteroglóssica que constitui seus diferentes sujeitos e que geram suas forças centrífugas.

Entendemos a sala de aula como um espaço de desenvolvimento de atividades cognitivas bem como de constituição de sentidos e produção de saberes, palco de conflitos e tensões. Os sujeitos envolvidos nos processos de interação aqui vivenciados falam de lugares diferentes e, como em toda enunciação pulsa o combate ideológico em suas diferentes formas discursivas, essa diversidade interfere diretamente no processo de ensino/aprendizagem. A ideologia de um poder exercido (garantido) sóciohierarquicamente exerce pressão nos reinos interligados da subjetividade e da linguagem. Essa só existe na medida em que é realizada em algum tipo de material semiótico, seja ele na forma de "discurso interior", seja nos processos de interação verbal, ou em formas mediadoras como a arte e a literatura. O domínio da ideologia coincide com o domínio dos signos. Por isso, a linguagem é entendida como uma prática social, constitutiva da realidade social, como discurso (BAKHTIN, 1988. p. 71).

Uma enunciação falada, ou escrita, se expressa sempre de um ponto de vista (uma voz). Compreender uma enunciação envolve um processo em que outras enunciações são buscadas e confrontadas entre si, marcando a atitude de quem ouve em relação ao sujeito que fala:

Compreender a enunciação de outrem significa orientar-se em relação a ela, encontrar o seu lugar adequado no contexto correspondente. A cada palavra que estamos em processo de compreender, fazemos corresponder uma série de palavras nossas, formando uma réplica. Quanto mais numerosas e substanciais forem, mais profunda e real é a nossa compreensão. (BAKHTIN, 1997. p. 132)

De acordo com Bakhtin, compreender sem julgar é impossível (1997, p. 382). Sendo assim, criticar (entendendo "crítica" como nossa capacidade de julgar) é um ato intrínseco ao ato de leitura. No jogo interativo de aulas de leitura literária, a compreensão da voz do aluno são condição para que o ato de leitura seja realizado de forma significativa. Ao ouvirem a voz da cultura de seus ancestrais valorizadas no/pelo texto literário, nossos leitores se identificam em suas raças e etnias. Ao mesmo tempo, a compreensão de suas 
vozes ocorre na medida em que o professor-mediador se insere e passa a fazer parte da comunidade de fala do contexto escolar.

Nessa visão, todo enunciado dialoga com seu meio, reflete e refrata seu redor. Este é o princípio do dialogismo: a relação necessária de qualquer enunciação com outras enunciações. A palavra encontra em seu caminho na direção do objeto em questão um ambiente dialógico cheio de tensões e interrelações. Ela vem à tona com algumas, filia-se a outras, nega tantas outras. Não é presa a um significado fixo, mas definido em seu contexto. Tudo isto dá forma ao discurso, deixa marcas na subjetividade dos sujeitos envolvidos em cada contato interativo.

Assumindo, a priori, a ideia de sala de aula como local onde diferentes discursos devem estar presentes como forma de obtenção de senso crítico dos estudantes. Para isso, faz-se necessário desvelar os efeitos do racismo nos níveis macro e microestruturais da sociedade brasileira. Junto ao conhecimento histórico, estes fatores trazem à sala de aula identidades sociais que dão voz coletiva a diferentes discursos racializantes, em diferentes épocas, desafiando a ideologia do mito racial brasileiro. A formação do professor mediador é fundamental para que isso aconteça. Ler a cultura dialogicamente (e, sempre que necessário, oposicionalmente), é antes de tudo, um posicionamento ético diante da variedade de vozes. O embate entre discursos racistas e antirracistas fundamentam nossa crença em uma prática decolonial do ensino da literatura para a diversidade étnico-racial no Brasil.

\section{De Leitor para Leitor: ações afirmativas e o ensino da literatura étnico-racial no}

\section{Brasil}

O Edital Fapemig/Capes/Educação Básica-2012 de pesquisa aplicada foi inédito por viabilizar diálogo entre professores da escola básica e professores universitários ao longo de três anos. Os projetos selecionados nesse edital tiveram incentivo financeiro para os professores da educação básica e verba para viabilização dos trabalhos. 
O desenvolvimento da pesquisa aplicada De Leitor para Leitor ocorreu nas seguintes etapas:

- A professora apresentava a coleção de livros aos alunos. A cada sete dias, espalhava diversos livros em uma das mesas da biblioteca para que eles escolhessem.

- Após a leitura, os alunos produziam resenhas a partir de orientações da professora sobre a forma e o conteúdo no processo de escrita: sintetizar o enredo sem contar o final da estória. Suscitar curiosidade sobre conhecimentos e práticas culturais africanas e afro-brasileiras encontrados na leitura. Depois de revisados e reescritos, os textos eram expostas em um mural no pátio da escola para incentivar alunos de outras turmas a lerem os livros do Kit-Afro. Outras atividades produzidas ao longo do ano foram colocadas em espaços coletivos da escola : desenhos, máscaras, poemas e artesanatos. Foram escritas em média 8 resenhas por aluno por ano em turmas de 25 a 30 alunos. O encerramento das trabalhos em cada turma contava, também, com oficina de penteados afro, apresentação de capoeira e discussões de avaliação do projeto.

- Gravação e disponibilização no Canal do You'Tube: <https://www. youtube.com/channel/UC3DJ7UdGuq5SJd_Cui0r7AA > dos recontos orais dos livros feito pelos alunos.

- Produção de Catálogo de Literatura Africana e Afro-brasileira pela professora supervisora e pela professora coordenadora.

Imagem 1 - Capa Catálogo Livros Literatura Infantil e Juvenil

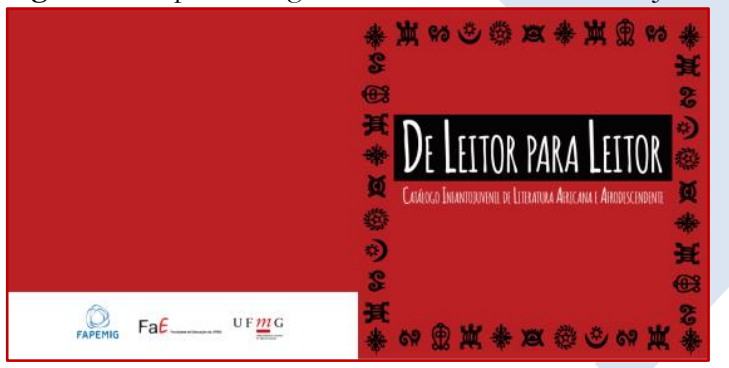

Fonte: Foto do autor 
Diante das resenhas e das avaliações escritas pelos alunos, foi possível notar alguns resultados. No âmbito sociocultural, notamos a tomada de consciência sobre discriminação, preconceito, racismo e diversidade. Também, a ideia de leitura literária como hábito, o aprendizado do uso da biblioteca e o compartilhamento de significados. Outros resultados foram notados em relação a aspectos cognitivos e apropriação de habilidades de leitura/escrita, como a capacidade de síntese e análise, a reflexão crítica, a identificação de gêneros orais e escritos, o uso de diferentes suportes textuais e a organização textual de forma coerente e coesa, depois de, pelo menos, duas reescritas.

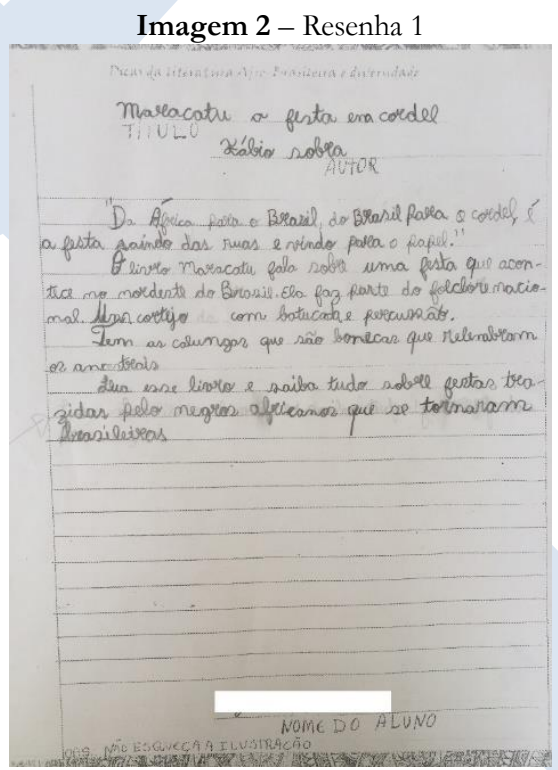

Fonte: Foto do autor

Vários títulos do Kit-Afro citam e descrevem práticas culturais dos povos do continente africano trazidos para o Brasil e que se tornaram brasileiras, configurando-se como livro informativo e não necessariamente ficcional, como por exemplo a série Africanidades da Editora Saraiva e Maracatu, a festa em Cordel, de Pedro Sombra. Retomando as orientações sobre o gênero textual resenha, notamos a síntese do enredo a partir da citação 
direta do texto que, de fato, apresenta o livro de forma concisa. Logo depois, são apresentados os conhecimentos e práticas culturais africanas e afro-brasileiras encontrados na leitura. $\mathrm{O}$ final, reservado ao incentivo à leitura, traz a curiosidade pelos saberes culturais trazidos pelos escravizados e suas contruções e contribuições na formação cultura brasileira contemporânea. A memória viva presente na festa nordestina consagra a resistência cultural ao longo dos anos de Colônia e do Brasil República.

\section{Imagem 3 - Resenha 2}

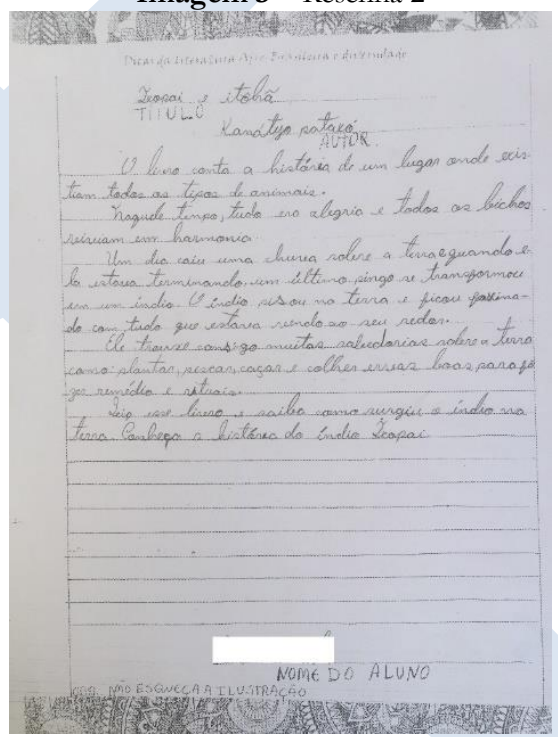

Fonte: Foto do autor

A cosmogonia Pataxó escrita por um autor Pataxó. Ainda que não tratemos especificamente do debate em torno de autoria e lugar de fala (RIBEIRO, 2017), pauta atual dos Movimentos Sociais no Brasil, constatamos que a representatividade de autores indígenas e negros ainda é incipiente na seleção do Kit-Afro. Em relação à produção da resenha, note-se os marcadores temporais naquele tempo e um dia trazendo um tom poético à sintese textual ao mesmo tempo em que denota a apreensão da estrutura da narrativa e os seus deslocamentos que fazem a trama seguir adiante. Os conhecimentos do povo 
Pataxó são apresentados e a resenha é finalizado com certo suspense, deixando ao possível leitor a curiosidade sobre como o índio surgiu e suas contribuições para o mundo na visão Pataxó.

Nas avaliações escritas pelos alunos do Projeto De Leitor para Leitor, é possível notar a voz e a tomada de consciência sobre preconceitos e estereótipos em torno de questões de gênero e sobre o racismo à brasileira:

"Eu achei o assunto interessante porque faz o bem para as pessoas. O livro que me marcou foi o cabelo de Cora que fala sobre discriminação racial."

"Eu já sofri racismo e minha mãe também já. O livro que mais gostei foi Chuva de Manga, que fala de um país africano chamado Chad."

"Eu gostaria que todos os meus colegas lessem esse livro pra ver como ele é importante para eles como foi para mim."

"Eu estou achando o projeto muito legal porque ele despertou um outro jeito de ver a história dos africanos"

"O livro que me marcou foi "Rap Rua" porque ele fala de umas pessoas que antes eu não percebia. Ele modificou o meu jeito de ver as pessoas de rua."

"O projeto é muito bom porque despertou em mim curiosidade e ajuda na leitura. O livro que mais me marcon foi Minisaia, baton e Futebol - as meninas que jogam futebol', porque ele me ensinou que não podemos fazer preconceito com as meninas do futebol, pois elas são muito boas."

"Estou gostando do projeto porque ele ensina que não pode preconceito. Por exemplo: eu vou chamar a outra pessoa de gorda, então, eu já penso: não posso fazer isso porque en estou fazendo um projeto e ele me despertou para essas coisas que não podemos fazer com os outros. O livro que li e me chamou mais atenção foi 'Entre meio sem babado'. Ele ensina a respeitar as pessoas e os adultos"

\section{Considerações Finais}

Na dinâmica de uma sociedade construída sob o sistema do capital e da imposição sociocultural norte-americana e europeias, como a sociedade brasileira, é importante admitir o racismo estrutural nas instituições de ensino, nos materiais didáticos e na literatura. Um dos nossos desafios continua sendo mostrar que a negação da questão racial 
é uma armadilha discursiva (OLIVEIRA, 2016) em que reproduzimos ideologias dos países que dizem ter nos colonizado.

Vemos, hoje, no Brasil a luta entre a recusa em se discutir o racismo e a proeminência do Movimento Negro, incentivando gradativamente estudantes, sociedade civil e universidades a debater e desmistificar a História Oficial. Certamente, a formação e valorização do professor da educação básica e a justa divisão de renda em nosso país, dentre tantas outras ações, não podem ser esquecidas. No entanto, no que tange aos estudos da linguagem, nossa contribuição para a Educação brasileira deve estar comprometida com o reconhecimento de obras canônicas que trazem ideologias racistas.

Os resultados alcançados pela pesquisa aplicada De Leitor para Leitor mostram como o reconhecimento da identidade dos alunos é importante para a motivação e a formação do hábito da leitura literária. Notamos, na avaliação dos alunos, a tomada de consciência sobre representações estereotipadas e preconceituosas que constituem o imaginário social e que devem ser criticadas tendo em vista o ensino da literatura para a diversidade etnicoracial brasileira. Políticas de formação de leitores comprometidas com o combate ao racismo, como realizadas pela RME-BH através da distribuição do Kit-afro de literatura afro são essenciais para a efetivação das Leis 10.639/2003 e 11.645/2008. Apesar do longo caminho a percorrer, a construção de pedagogias decoloniais e a produção de literaturas que permitem a construção de outros discursos de valor, outros paradigmas críticos já fazem parte da Educação étnico-racial no Brasil.

\section{READER TO READER: ETHNICAL AND RACIAL RELATIONS AND CHILDREN LITERATURE TEACHING IN BRAZIL}

ABSTRACT: This paper discusses racial relations in teaching of children's and young literature in Brazil. Based on the laws 10.639/2003 and 11.645/2008, which require that Brazilian schools teach the history and culture of Afro-Brazilians and Native Nations, we seek to problematize the applied research project From Reader To Reader, considering the effectiveness of the cited laws and the receiving of the African and Afro-Brazilian literary books brought together in Kit Afro: an affirmative policy of democratization of the access to literary production for diversity implemented by the Municipal Teaching Network of Belo Horizonte . Our discussions are guided by studies about etnic and racial relations in Brazil (GOMES, 2012), Critical Discourse Analysis (VAN DIJK, 2008) and Teaching Literature (OLIVEIRA, 2015;2016) and intercultural and decolonial pedagogy 
(HOPENHAY, 2009; WALSH, 2017). Based on the reviews and evaluations produced, we point out the linguistic-ideological awareness of the students involved.

KEYWORDS: Racial education; child and youth literature teaching; Affirmative policies;

\section{REFERÊNCIAS}

AUSTIN, John Langshaw. How to Do Things with Words. Cambridge: Harvard University Press, 1975.

BAKHTIN, M. Marxismo e filosofia da linguagem. São Paulo: Hucitec, 1992.

BOURDIEU, Pierre. A economia das trocas linguísticas. São Paulo: Perspectiva, 1982.

FOUCAULT, Michel. A arqueologia do saber. Rio de Janeiro: Forense Universitaria, 2012.

FREIRE, Paulo. Conscientização: teoria e prática da libertação: uma introdução ao pensamento de Paulo Freire. São Paulo: Cortez e Moraes, 1979.

GOMES, Nilma Lino. Relações étnico raciais educação de descolonização dos currículos. Currículo sem Fronteiras, v. 12, n. 1, pp. 98-109, Jan/Abr 2012.

GONÇALVES, L. A; SILVA, P. B. Prática do racismo e formação de professores. In: DAYRELL, Juarez. Múltiplos olhares sobre educação e cultura. Belo Horizonte: UFMG, 1996.

GUMPERZ, John Joseph. Language and Social Identity. Cambridge: Cambridge University Press, 1982.

HEATH, Shirley Brice. The functions and uses of literacy. In: CASTELL, Suzanne de; LUKE, Allan; EGAN, Kieran (Ed.). Literacy, Society, and Schooling: A reader. USA: Cambridge University Press, 1986. p. 15-25.

HOPENHAY, Martín. La educación intercultural: entre la igualdad y la diferencia. In: CANCLINI, Néstor García; MARTINELL, Alfons. (Coord.). El poder de la diversidad cultural. Pensamiento Iberoamericano. Madrid, v. 1, n. 4, may. 2009.

LABOV, William. Sociolinguistic Patterns. Philadelphia: University of Pennsylvania Press, 1972.

LABORNE, A. A. de P. Branquitude em foco: análises sobre a construção da identidade branca de intelectuais no Brasil. Belo Horizonte. 156 f. Tese (Doutorado em Educação) Faculdade em Educação, Universidade Federal de Minas Gerais, Belo Horizonte, 2014.

MARX, Karl; ENGELS, Friederich. O manifesto comunista. São Paulo: Martins Fontes, 1998.

MINISTÉRIO DA EDUCAÇAO/Secretaria da Educação Continuada, Alfabetização e Diversidade. Orientações e ações para a educação das relações étnico-raciais. Brasília, SECAD, 2006. 
MUNANGA, Kabengele; GOMES, Nilma Lino. O negro no Brasil de hoje. Global: São Paulo, 2006.

OLIVEIRA, Míria Gomes de. O ensino da leitura e da literatura no ensino médio brasileiro: Controvérsias, diversidade e polifonia. Revista Portuguesa de Educação, v. 27, n. 1, 2014a.

. Interação, utopia e a construção de uma escola inclusiva. ALFA: Revista de Linguistica. v.58, n.3, 2014b.

. Formação Inicial de Professores e o ensino da Literatura para a diversidade: Machado sem máscaras. Percussos, v. 17, n. 35, 2016.

; SILVA, Paulo V. B. Educação Étnico-Racial e Formação Inicial de Professores: a recepção da Lei 10.639/03. Educação e Realidade, v. 42, n. 1, 2017.

PÊCHEUX, Michel. O Discurso: estrutura ou acontecimento. Campinas: Pontes, 1983.

ROGERS, Rebecca. An Introduction to Critical Discourse Analysis in Education. New Jersey: Erlbaun Publishers, 2004.

SANTOS, Boaventura de Sousa (Org.) Epistemologias do Sul. São Paulo: Cortez. 2010.

SEARLE, John. Intentionality, an Essay in the Philosopby of Mind. New York: Cambridge University Press, 1983.

SILVA, Paulo Vinícius Baptista da; ROSEMBERG, Fúlvia. Brasil: lugares de negros e brancos na mídia. In: VAN DIJK, Teun A. Racismo e discurso na América Latina. São Paulo: Contexto, 2008.

SILVA, Petronilha Beatriz Gonçalves. Africanidades brasileiras: esclarecendo significados e definindo procedimentos pedagógicos. Revista do Professor. Porto Alegre, 19 (73):26-30, jan./mar. 2008.

STREET, Brian. V. Literacy Theory and Practice. Cambridge University Press, 1984

SOUZA, Florentina da S. Afro-decendência em Cadernos Negros e Jornal do MNU. Belo Horizonte: Autêntica, 2005.

VAN DIJK, Teun A. Racismo e discurso na América Latina. São Paulo: Contexto, 2008.

WALSH, Catherine. Pedagogías decoloniales. Prácticas insurgentes de resistir, (re)existir e (re)vivir. Serie Pensamiento Decolonial. Editora Abya-Yala. Equador, 2017.

WITTGENSTEIN, Ludwig. Philosophical Investigations. Oxford: Basil Blackwell, 1953.

Recebido em: 12/04/2020.

Aprovado em: 07/05/2020. 